I was fortunate enough to work with him for many years and owe him a debt that I am unable, fully, to express as a colleague, a friend and a family man. He had the support of his wife, two sons and daughter at all times. Only his daughter followed him into the medical profession, his sons taking after his other interest in the theatre. He himself was a fine actor, a producer and authority on English literature. His interest in natural history continued to his last days. He was a keen gardener and bred many somewhat esoteric animals in his collection of glasshouses.

A much loved man who will be sadly missed.

David M. Carter

\section{Professor Rashid Chaudhry}

Formerly Emeritus Professor and Chairman, Fountain House, Lahore, Pakistan

Professor Rashid Chaudhry died in Lahore on 13 August 2000. He was a pioneer in establishing psychiatry in Pakistan and started the first department of psychiatry in a general hospital in the country in the late 1960s and set the scene for expansion of this speciality in Pakistan. He was the first Professor of Psychiatry at King Edward Medical College, Lahore, and had served more than 15 years when he retired in 1982

He was born in East Punjab and his family migrated to Pakistan in 1947. After graduating from King Edward Medical College he joined the Army Medical Corps and served in northern areas for about 2 years. He then proceeded to the UK for further study at the Maudsley, after which he started his career as a specialist at the Mental Hospital, Lahore. He was elected FRCPsych in 1972

His vision to establish psychiatry as an important branch of medicine was reflected in his efforts to create more insight into mental health problems both among professionals and the general public. He also initiated the rehabilitation psychiatry in the country andfounded a rehabilitation facility in the name of 'Fountain House' at Lahore.
This facility is now regarded as an important innovation and is now widely accepted as a medium for treatment and training.

Professor Rashid Chaudhry was respected for his work and expertise all over the world. He was elected office bearer of different International organisations. He received various awards from the Government of Pakistan, United Nations Organization, World Health Organization, world psychiatric bodies and voluntary organisations. He was also very active in establishing the World Islamic Association for Mental Health and served this organisation as its president for more than 5 years.

He will be remembered by a large number of friends, associates and students. His dedication and contribution in the field of mental health will continue providing inspiration for his fellow colleagues in Pakistan. May God rest his soul in peace and give strength to his family and friends to bear his loss.

Afzal Javed

\title{
reviews
}

\section{Developing Primary Care for Patients with LongTerm Mental Illness. Your Guide to Improving Services}

By R. Byng, H. Single \& C. Bury. Kings Fund. 1999. 115 pp. f12.99 (pb). ISBN: 1-85717-271-X.

Books about general practice are interesting. Books about general practice written by non-general practitioners (GPs) telling us how to do it are often quite fun. Books about general practice written by GPs are useful; books written about general practice by a practising GP are rare and valuable. This book falls into the latter category. What makes it more interesting still is that it covers a topic that is poorly covered by either the research literature or by other authors the care of the severely mentally ill in primary care.

The book is clearly set out, describes the steps needed to undertake the various tasks, identifies why the tasks are important and what will be achieved by completing them. The descriptions throughout are simple, concise and designed with general practice in mind.

This is a book that is aimed (successfully) at primary care, but its attraction does not end there. It is of value to community mental health teams (CMHTs) in helping them understand some of the strengths and weaknesses of primary care, and what CMHTs can do to support primary care provide high quality care to a vulnerable population. It is of value to managers in primary care groups to help them provide direction to a mental health special interest group, always difficult if the managers themselves have no experience of commissioning or developing primary care mental health services. Overall it is a useful, well constructed book.

There is but one drawback - this review is published in a psychiatric journal, and not a primary care journal, which would raise the level of awareness significantly.

Alan Cohen FRCGP Head of Primary Care, Sainsbury Centre for Mental Health

\section{Primary Prevention of Mental, Neurological and Psychosocial Disorders}

World Health Organization. Geneva: WHO. 1998. 113 pp. SW.fr. 35-, Sw.fr. 24.50 in developing countries. ISBN: 92-4-154516-X.

This fairly short document forms the latest part of the World Health
Organization's (WHO) series of publications on mental disorder. It is aimed at professionals and policy makers in a variety of sectors who may be concerned with or who are in a position to influence the prevention of mental disorders. This is a welcome enterprise that can only serve to raise the profile of this neglected area.

The book provides a useful summary of our current medical knowledge of how to prevent four largely unrelated phenomena: mental retardation (i.e. learning disabilities), epilepsy, suicide and 'burnout'. However, it is seriously flawed in terms of the brief set by the WHO. It does not really attempt to address the wider interests of policy makers, neither does it present much of a coherent strategy for the prevention of mental disorders. Indeed, it is not clear that the four 'conditions' chosen make sense as the focus for a prevention strategy or that they sit naturally together either conceptually or practically. In many countries the agencies concerned with the prevention and 'treatment' (if relevant) of these conditions will be different.

The model adopted throughout is what is often, lazily, referred to as 'the medical model'. Information about the conditions is conceived of in purely medical terms and interventions are limited to the obvious traditional public health approaches. It is as if the authors have ignored the last 40 years of practice in 